See Article page 1096.

\section{Commentary: The three Cs of a successful heart center intensive care unit: Cooperation, coordination, and communication}

\author{
Kenneth T. Shelton, MD, ${ }^{a}$ and Thoralf M. Sundt, MD $^{\mathrm{b}}$
}

We read with interest the article by Kennedy-Metz and colleagues on the importance of high-performing teams in the cardiovascular intensive care unit (ICU) in the current issue of the Journal. ${ }^{1}$ The authors focus on cooperation, coordination, and communication as key elements of a highperforming cardiovascular intensive care "action" team, and conclude with a review of failure to rescue as a way of assessing high-functioning critical care programs and a strategy to further study and compare cardiovascular ICUs. Cardiovascular critical care medicine has undergone an evolution of care as cardiac patients have become more medically complex. ${ }^{2}$ As a busy Heart Center ICU in a quaternary hospital in Boston, we applaud the authors for focusing on this important topic. Over the past 5 years, we have created a multidisciplinary, cross-specialty and interprofessional team of critical care providers in a patient-centered care model.

The authors review the impact of teamwork, the handover process, and failure to rescue to highlight a successful model of care. This is especially true during the COVID19 pandemic, when teams are physically separated but forced to maintain the same level of teamwork, often on a virtual platform. The daily review of chest X-rays, daily huddles to discuss patient throughput, daily bedside rounds, weekly staff meetings, and monthly clinical operational meetings, in addition to morbidity and mortality conferences, are all part of successful cardiovascular critical care programs.

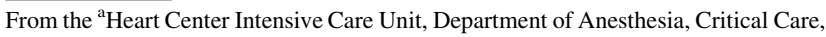
and Pain Medicine, and ${ }^{\mathrm{b}}$ Division of Cardiac Surgery, Department of Surgery, Massachusetts General Hospital, Harvard Medical School, Boston, Mass.

Disclosures: The authors reported no conflicts of interest.

The Journal policy requires editors and reviewers to disclose conflicts of interest and to decline handling or reviewing manuscripts for which they may have a conflict of interest. The editors and reviewers of this article have no conflicts of interest.

Received for publication March 19, 2021; revisions received March 19, 2021; accepted for publication March 23, 2021; available ahead of print March 30, 2021.

Address for reprints: Thoralf M. Sundt, MD, Division of Cardiac Surgery, Department of Surgery, Massachusetts General Hospital, 55 Fruit St, Boston, MA 02114 (E-mail: tsundt@mgh.harvard.edu).

J Thorac Cardiovasc Surg 2022;163:1105-6

$0022-5223 / \$ 36.00$

Copyright (C) 2021 by The American Association for Thoracic Surgery

https://doi.org/10.1016/j.jtcvs.2021.03.085
}

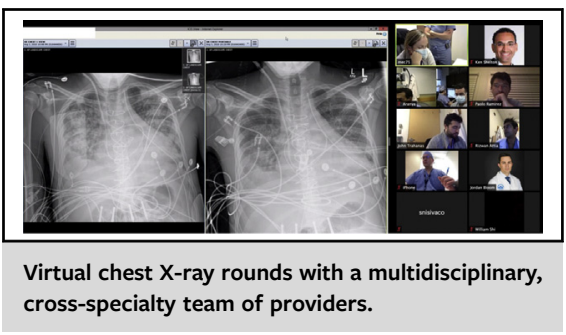

CENTRAL MESSAGE

Cardiac intensive care medicine has transitioned from a clinical service care model to a patientcentered care model requiring exceptional teamwork to drive successful patient outcomes.

Professional relationships in critical care allow providers to maintain the highest level of care. While cardiovascular critical care programs may differ in provider staffing ratios, open versus closed models of care and ICU capacity, interprofessional interactions and trust are imperative to every successful program. This is especially true when caring for surgical patients with established patient-provider relationships.

The authors also focus on two emerging concepts in adult cardiovascular critical care: family-centered care $^{3}$ and teamwork during times of crisis. Maintaining healthy professional relationships is necessary to provide appropriate physical and emotional support during times of crisis. ${ }^{4}$ The psychological impact of the COVID-19 pandemic for patients, families, and providers is unlike anything we have experienced in recent medical history. Maintaining family involvement at the bedside has perhaps never been more challenging as during the COVID-19 pandemic. While hospital restrictions exist to prevent hospital and community viral spread, these restrictions can also socially isolate patients and providers. This has forced critical care teams to find creative virtual methods of ensuring family engagement for patients and teamwork among providers.

In conclusion, teamwork in a modern cardiovascular critical care unit relies on the trust formed through professional relationships while including the extended team of family members supporting our patients. The authors focus on cooperation, coordination, and communication as key elements of a high-performing cardiovascular intensive care "action" team. This is perhaps never more important than during the COVID-19 pandemic, when social distancing 
has forced us to rethink and reimagine ways of maintaining the core values of patient- and family-centered teamwork in critical care. $^{5}$

\section{References}

1. Kennedy-Metz LR, Barbeito A, Dias RD, Zenati MA. Importance of highperforming teams in the cardiovascular intensive care unit. J Thorac Cardiovasc Surg. 2022;163:1096-104.
2. Fuster V. The (R)evolution of the CICU: better for the patient, better for education. J Am Coll Cardiol. 2018;72:2269-71.

3. Yoo HJ, Shim JL. The effect of a multifaceted family participation program in an adult cardiovascular surgery ICU. Crit Care Med. 2021;49:38-48.

4. Traylor AM, Tannenbaum SI, Thomas EJ, Salas E. Helping healthcare teams save lives during COVID-19: insights and countermeasures from team science. Am Psychol. 2021;76:1-13.

5. Rose L, Yu L, Casey J, Cook A, Metaxa V, Pattison N, et al. Communication and virtual visiting for families of patients in intensive care during COVID-19: a UK national survey. Ann Am Thorac Soc. February 22, 2021 [Epub ahead of print].
See Article page 1096.

\section{Commentary: Teamwork makes the dream work: We learned it in kindergarten, but did we lose it along the way?}

\author{
Gabor Bagameri, MD, and John M. Stulak, MD
}

The expression, teamwork makes the dream work means that a team must have a common goal, a shared mental model, and must work together to achieve it. For a team to be successful, team members must put the interest of the team above their own. These are timeless truths with origins extending far back to the dawn of human evolution. Among the first things we learn as children in kindergarten is the need to work together. While we learn to cooperate with each other as young children, we develop solid skills of problem solving, communication, listening, creativity, and self-esteem. Despite our long evolutionary and personal history of cooperation, we have not yet mastered the concept of teamwork. To create a high-performing team is not an easy task, and the challenges of teamwork have long been recognized. Among the possible reasons for

From the Department of Cardiovascular Surgery, Mayo Clinic College of Medicine and Sciences, Rochester, Minn.

Disclosures: The authors reported no conflicts of interest.

The Journal policy requires editors and reviewers to disclose conflicts of interest and to decline handling or reviewing manuscripts for which they may have a conflict of interest. The editors and reviewers of this article have no conflicts of interest

Received for publication June 10, 2021; revisions received June 10, 2021; accepted for publication June 10, 2021; available ahead of print June 17, 2021.

Address for reprints: John M. Stulak, MD, Department of Cardiovascular Surgery, Mayo Clinic College of Medicine and Sciences, 200 First St, SW, Rochester, MN 55905 (E-mail: Stulak.john@mayo.edu).

J Thorac Cardiovasc Surg 2022;163:1106-7

0022-5223/\$36.00

Copyright (c) 2021 by The American Association for Thoracic Surgery

https://doi.org/10.1016/j.jtcvs.2021.06.017
Check for updates

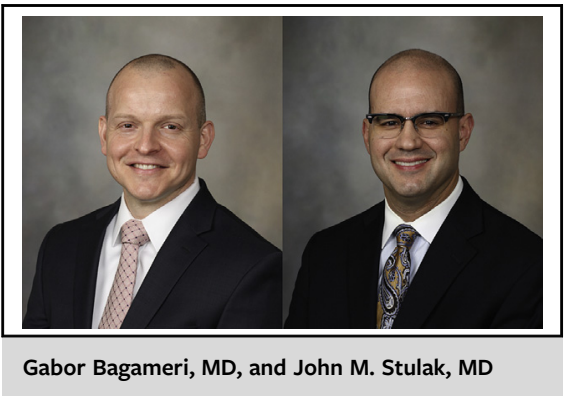

CENTRAL MESSAGE

Team members must put the

interest of the team above their

own. Health care is not error-free

but the ultimate goal is to trans-

form health care into a high-

reliability organization.

this breakdown could be the central metaphor used by Jonathan Haidt in his book, ${ }^{1}$ Righteous Mind: Humans are $90 \%$ chimpanzee and $10 \%$ bees. During our evolutionary and personal journey, we compete at both an individual and group level simultaneously, and this can create a split in successful teamwork.

In their article, Kennedy-Metz and colleagues ${ }^{2}$ artfully describe the importance of high-performing teams in cardiovascular intensive care units. Cardiovascular intensive care units are "complex, dynamic, and time-pressured" environments, medical care across all landscapes is becoming increasingly more complex, thus requiring high-performing teams across all medical specialties. Safety is a basic patient expectation and right in health care. The landmark publication, ${ }^{3}$ To Err is Human, by the Institute of Medicine showed that the health care is not error-free, and in fact, medical errors are a leading cause of death in the United States. The ultimate goal is to transform health care into a high 